\title{
Gender differences in colorectal cancer: implications for age at initiation of screening
}

\author{
H Brenner,', M Hoffmeister', V Arndt' and U Haug' \\ 'Division of Clinical Epidemiology and Aging Research, German Cancer Research Center, Bergheimer Strasse 20, D-69II 5 Heidelberg, Germany
}

There is some variation regarding age at initiation of screening for colorectal cancer (CRC) between countries, but the same age of initiation is generally recommended for women and men within countries, despite important gender differences in the epidemiology of CRC. We have explored whether, and to what extent, these differences would be relevant regarding age at initiation of CRC screening. Using population-based cancer registry data from the US and national mortality statistics from different countries, we looked at cumulative 10-year incidence and mortality of CRC reached among men at ages 50, 55, and 60, and found that women mainly reached equivalent levels when 4 to 8 years older. The gender differences were remarkably constant across populations and over time. These patterns suggest that gender differentiation of age at initiation may be worthwhile to utilise CRC-screening resources more efficiently.

British Journal of Cancer (2007) 96, 828-83I. doi: I0.1038/sj.bjc.6603628 www.bjcancer.com

Published online 20 February 2007

(C) 2007 Cancer Research UK

Keywords: colonoscopy; colorectal cancer; prevention; sigmoidoscopy

With more than one million new cases and more than 500000 deaths per year, colorectal cancer (CRC) is the third commonest cancer and the fourth commonest cancer cause of death worldwide (Parkin et al, 2005). Owing to its typically slow development, there is a large potential for reducing the burden of the disease by early detection and removal of precancerous lesions or early cancer stages. Various screening examinations, including faecal occult blood testing (FOBT), sigmoidoscopy, and colonoscopy have meanwhile been recommended by expert committees and implemented in screening offers in a number of countries (e.g. Winawer et al, 2003; Schmiegel et al, 2004; Malila et al, 2005; Smith et al, 2006). Regarding the age at initiation of screening, which is a crucial parameter for the effectiveness and cost-effectiveness of screening programmes (Vijan et al, 2001), there is some variation between countries (typically ranging from 50 to 60 years for the population at average risk). However, within countries, the same age of initiation is generally recommended for women and men, despite important gender differences in the epidemiology of CRC. In particular, age-specific CRC incidence and mortality are lower in women than in men, which implies that women reach comparable levels of CRC incidence and mortality at higher ages than men. This paper aims to address the question whether and to what extent these epidemiological differences might be relevant for defining age at initiation of CRC screening among women and men.

*Correspondence: Professor H Brenner;

E-mail: h.brenner@dkfz-heidelberg.de

Received 12 December 2006; revised 15 January 2007; accepted 19 January 2007; published online 20 February 2007

\section{METHODS}

\section{Outcome measure}

When attempting to translate the gender differences in the epidemiology of CRC into gender-specific ages at initiation of screening, it is first necessary to define an appropriate outcome measure. In a screening programme that primarily aims at the early detection of CRC, as applies to FOBT-based screening, (cumulative) age- and sex-specific CRC incidence appears to be a natural choice. In a screening programme that aims to detect both CRC and its precursors (adenomas), as applies to endoscopy-based screening, the epidemiology of adenomas might also be considered. However, if the time period until adenomas progress to cancer is independent of age and sex, additional consideration of adenoma occurrence would have no impact on the results. If, on the other hand, progression time differs by age and sex, genderspecific differences in CRC incidence may actually remain the more relevant parameter even for these types of CRC screening programmes. When data on CRC incidence are not available, ageand sex-specific CRC mortality can be used as a good surrogate parameter, given that survival differences between female and male CRC patients are very small (Bossard et al, 2007).

\section{Data sources}

Age and sex specific data on CRC incidence and mortality were obtained for the years 2000-2003 in the US from the National Cancer Institute's Surveillance, Epidemiology and End Results (SEER) Programme (Ries et al, 2006). The incidence data are based on 17 areas of the US (Atlanta, Connecticut, Detroit, Hawaii, Iowa, New Mexico, San Francisco-Oakland, Seattle-Puget Sound, Utah, Los Angeles, San Jose-Monterey, Rural Georgia, Alaska, Greater 
California, Kentucky, Louisiana, and New Jersey). The mortality data are based on US national figures.

In addition, the World Health Organisation (WHO) mortality database, accessed through the website of the International Agency for Research on Cancer (WHO mortality data base, 2006), was used to assess the consistency of observed patterns between populations. National age- and sex-specific mortality data referring to the year 2001 were obtained for 11 large countries from different parts of the world: Australia, Asia (Russia, Japan), Europe (France, Germany, Italy, Poland, Spain, United Kingdom), and North America (Canada, US). Although data up to the year 2003 were available for some countries, the latest available data were from 2001 for other countries; we therefore chose this year for our comparative analyses. Finally, US national mortality data from the years 1976, 1981, 1986, 1991, 1996, and 2001 were obtained from the WHO-mortality database to address consistency of observed patterns over time.

\section{Statistical analysis}

Using the SEER incidence data, we first calculated cumulative CRC incidence within the following 10 years among men and women for each single year of age between ages 50 and 75 . The cumulative incidence within a given age range approximates the expected risk of developing a disease within the defined age interval in the absence of competing causes of death, assuming that age specific incidence rates remain constant over time (Day, 1987). Starting from the levels of 10-year cumulative incidence among men at ages 50,55 , and 60 (the most commonly implemented ages for initiation of CRC screening in existing programmes), we determined at what ages the same levels of 10-year cumulative incidence were observed among women. Analogous calculations of 'risk advancement periods' (Brenner et al, 1993) were then carried out for 10-year cumulative mortality on the basis of the national vital statistics data. In additional sensitivity analyses, the time interval was varied between 5 and 15 years.

\section{RESULTS}

The SEER incidence database included 74111 men and 72290 women diagnosed with CRC in 2000-2003. Among men, cumulative incidence in the subsequent 10 years increased from $0.8 \%$ at age 50 to $1.2 \%$ at age 55 and $1.9 \%$ at age 60 (see Figure 1 ). Among women, comparable levels of 10-year cumulative incidence

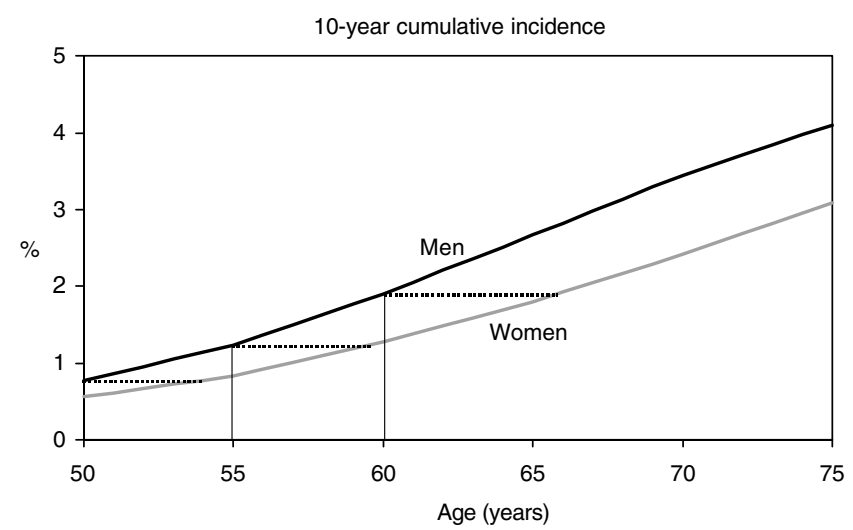

Figure I 10-year cumulative incidence of colorectal cancer in subsequent 10 years among men and women at various ages. The dotted lines indicate the age differences at comparable levels of cumulative incidence between women and men. SEER Program, US, 17 registries, 2000-2003 (Ries et al, 2006) were reached at ages 54,60 , and 66 only, i.e. 4,5 , and 6 years later, respectively.

Overall, 113174 men and 113454 women died of CRC in the US in 2000-2003. The 10-year cumulative mortality from CRC in the subsequent 10 years also steadily increased with age in both sexes, and it was higher at any age between 50 and 75 years among men than among women (see Figure 2). Cumulative mortality within the subsequent 10 years was $0.23,0.39$ and $0.63 \%$ at ages 50,55 and 60 , respectively, among men. Again, comparable levels were reached by women at ages 54,60, and 66 only, i.e. 4,5 , and 6 years later, respectively.

Sensitivity analyses using 5- and 15- rather than 10-year cumulative incidence and mortality in the US as indicators of CRC risk yielded very similar differences in the age at which comparable levels were reached among men and women (differences between 4 and 6 years for 5 -year cumulative incidence and mortality, and between 5 and 7 years for 15 -year cumulative incidence and mortality).

Analogous calculations for 10-year cumulative CRC mortality in 2001 in 11 large countries from different parts of the world showed very similar age differences between women and men, despite some major variation in the overall levels of CRC mortality (see Table 1). The 10-year cumulative mortality seen among men at age 50 was reached by women between ages 54 and 56 in nine out of 11 countries (median: 55 years); slightly lower and higher ages were only seen for the Russian Federation (52 years), and Japan (57 years), respectively. The 10 -year cumulative mortality seen among men at age 55 was reached by women between ages 60 and 62 in the same nine countries (median: 61 years). Again, slightly lower and higher ages were only seen for the Russian Federation (59 years) and Japan (64 years), respectively. The 10-year cumulative mortality seen among men at age 60 was reached by women between ages 66 and 68 in nine countries (median: 67 years) and at ages 69 and 70 in Spain and Japan, respectively.

A time trend analysis on the basis of 10-year cumulative CRC mortality for the US revealed that the sex differences were consistently seen throughout the 25-year period from 1976 to 2001. The sex differences even slightly increased over time.

\section{DISCUSSION}

Our analyses of age- and sex-specific incidence and mortality of CRC in the US and 10 other large countries from different parts of the world indicate that the lower incidence and mortality among women quite consistently translates to an age difference of approximately 4-8 years at which comparable levels of risk are

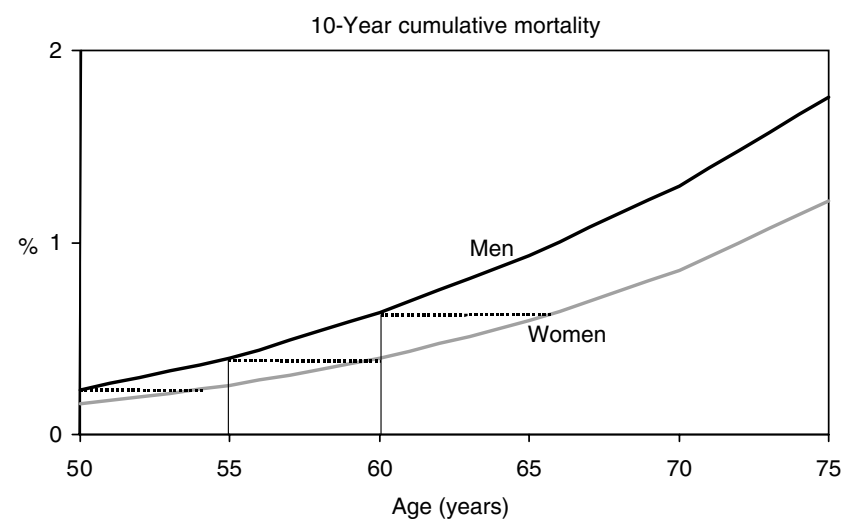

Figure 2 10-year cumulative mortality from $C R C$ in subsequent 10 years among men and women at various ages. The dotted lines indicate the age differences at comparable levels of cumulative mortality between women and men. US national mortality statistics, 2000-2003 (Ries et al, 2006). 
Table I Age-adjusted mortality of colorectal cancer among men and women, and ages at which I0-year cumulative mortality among women reaches levels observed among men at ages 50, 55, and 60

\begin{tabular}{|c|c|c|c|c|c|c|}
\hline \multirow[b]{2}{*}{ Country } & \multirow[b]{2}{*}{ Year } & \multicolumn{2}{|c|}{ Age-adjusted mortality ${ }^{a}$} & \multicolumn{3}{|c|}{$\begin{array}{l}\text { Age at which } 10 \text {-year cumulative mortality among women } \\
\text { reaches level observed among men at age }\end{array}$} \\
\hline & & Men & Women & 50 & 55 & 60 \\
\hline Australia & 2001 & 17.4 & 11.2 & 54 & 61 & 67 \\
\hline Canada & 2001 & 14.6 & 9.6 & 55 & 61 & 67 \\
\hline France & 2001 & 15.8 & 9.0 & 56 & 61 & 68 \\
\hline Germany & 2001 & 18.2 & 11.7 & 56 & 62 & 66 \\
\hline |taly & 2001 & |5.| & 9.3 & 54 & 61 & 68 \\
\hline Japan & 2001 & 16.4 & 9.5 & 57 & 64 & 70 \\
\hline Poland & 2001 & 18.7 & 11.5 & 55 & 61 & 68 \\
\hline Russian Federation & 2001 & 18.7 & 12.8 & 52 & 59 & 67 \\
\hline Spain & 2001 & 17.6 & 9.6 & 55 & 62 & 69 \\
\hline United Kingdom & 2001 & 15.9 & 9.5 & 55 & 62 & 67 \\
\hline United States & 2001 & 13.7 & 9.5 & 54 & 60 & 66 \\
\hline & 1996 & 15.0 & 10.3 & 53 & 60 & 67 \\
\hline & 1991 & 16.4 & 11.2 & 53 & 60 & 66 \\
\hline & 1986 & 17.4 & 12.3 & 53 & 59 & 65 \\
\hline & 1981 & 18.0 & 13.0 & 52 & 59 & 65 \\
\hline & 1976 & 18.8 & 14.5 & 52 & 59 & 65 \\
\hline
\end{tabular}

${ }^{a}$ Deaths per 100000 person years, adjusted to the world standard population.

reached. Colorectal cancer incidence and mortality at various ages are closely related to potential benefits of screening, which have to be weighed against costs and potential adverse side effects in choosing the age of screening initiation. Our analysis suggests that the balance in favour of screening is likely to be reached several years later among women than among men. This finding is supported by a recent study from Poland among more than 50000 participants of a colonoscopy-based screening programme, where prevalence of advanced adenomas was higher at each age among men than among women, prompting the authors to the conclusion that gender-specific CRC-screening recommendations may be warranted (Regula et al, 2006). Furthermore, there are indications both from our analysis and from the literature (Fernandez et al, 2001) that the gender difference in the epidemiology of CRC has steadily increased during the last few decades. These results may therefore have important implications for the offer of CRC screening programmes and their optimisation in terms of cost effectiveness.

The choice of different, risk adapted ages at initiation of screening is well accepted and established for CRC risk factors other than gender, in particular a history of CRC before age 60 in a first degree relative (Winawer et al, 2003; Schmiegel et al, 2004; Smith et al, 2006). Although the relative risk of CRC among people with such a family history compared to those without is larger than the relative risk of men compared to women (Johns and Houlston, 2001), the prevalence of the former risk factor in the population is much lower than the 'prevalence' of male gender. These patterns suggest that appropriate differentiation of age at initiation of CRC screening by gender might be similarly or even more relevant from a public health point of view than the widely practiced differentiation by family history.

Another important epidemiological aspect that might be of importance in the choice of age at initiation of CRC screening is the differential distribution of CRC location among women and men. The proportion of cancer in the distal colon and rectum is considerably lower among women than among men (Stewart et al, 1983; Bonithon-Kopp and Benhamiche, 1999; McCashland et al, 2001). Therefore, the sex difference in distal CRC occurrence is even larger than the sex difference in overall CRC occurrence. These patterns suggest that age differences may even be more relevant for initiation of screening programmes primarily based on sigmoidoscopy than for screening programmes primarily based on stool tests or colonoscopy.

Epidemiological data on the occurrence of colorectal neoplasms are important, but are not the only factors to be considered in the choice of the age range at which screening is offered. Another important factor is remaining life expectancy (Ko and Sonnenberg, 2005; Lin et al, 2006), which is of primary relevance for a potential upper age limit for CRC screening. Given that life expectancy is generally higher among women than among men, there are further reasons to define gender-specific age ranges for CRC screening.

Considering potential gender differences in recommended age ranges for CRC screening, nonepidemiological criteria, such as complexity of guidelines, also have to be taken into account (Lieberman, 2005). One might argue that gender-specific recommendations might add another layer of complexity, which could be a barrier against use of CRC screenings. However, from the patients' point of view, schedules for cancer screening are genderspecific anyway, given that some of the most widely used screening measures refer to female (breast, cervical) and male (prostate) cancers. From the point of view of health-care providers, initiation of CRC screening at different ages for women and men (e.g. 5 years apart) would not seem to be too much of a challenge either.

In the interpretation of our results, the following limitations should be kept in mind. Given the lack of national CRC incidence data for many countries, CRC-mortality data were used along with CRC incidence data in our comparative analyses. As already mentioned, CRC mortality should be a good surrogate parameter given that survival of female and male CRC patients is essentially the same (Bossard et al, 2007). In fact, exactly the same age differences by sex were seen for incidence and mortality in our analyses for the US, where both measures were looked at. Another potential limitation is that in some of the countries included in this analysis, some form of CRC screening has already been practiced during the calendar years included in the analyses. This may have affected CRC incidence and mortality to some extent. Furthermore, differential participation in CRC screening among women and men might have affected the gender differences reported in our analysis. However, in the years under investigation, the overall impact of CRC screening is likely to have been limited, and gender differences in screening utilisation quite small compared to the major gender difference in CRC incidence and mortality. In particular, participation in 
endoscopic screening examinations was slightly lower rather than higher among women compared with men in the US (Seeff et al, 2004; Lieberman et al, 2005; Meissner et al, 2006), and could thus not explain the lower CRC mortality among women.

Our analysis only considers the 'net differences' in CRC incidence and mortality between women and men, which might be owing to a variety of reasons. There are suggestions that hormonal effects, both up to menopause and through hormonal replacement therapy (HRT) may protect from or delay development of CRC (Beral et al, 2002). To the extent that the recent reduction in HRT use following publication of the results of the Women's Health Initiative Randomised Trial (Rossouw et al, 2002; Hersh et al, 2004) and the Million Women Study (Beral, 2003; Faber et al, 2005) might increase CRC incidence among women, the previous trend of an increasing gender gap in CRC incidence and mortality might be slowed down or possibly reversed.

Our analyses do not allow a general recommendation regarding the best age for initiation of CRC screening. The latter is likely to vary between populations, owing to between-population variation in CRC incidence and mortality, and in CRC screening and treatment costs. Our results suggest, however, that the optimal age for screening initiation is likely to be around 5 years higher for women than for men within populations, assuming that screening is equally effective in women and men. This could imply either postponement of age at initiation of screening among women or advancement of age at initiation among men compared to nongender-specific-screening schemes. It should also be kept in mind that our results pertain to people at average risk of CRC, and they should therefore not be generalised to specific screening strategies for high-risk groups.

In summary, our results suggest that gender specific differentiation of age at initiation of CRC screening by about 5 years might help to utilise screening resources in a more efficient manner. Gender specific screening schedules should therefore deserve careful attention in the design and evaluation of CRC screening programmes.

\section{REFERENCES}

Beral V, Banks E, Reeves G (2002) Evidence from randomised trials on the long-term effects of hormone replacement therapy. Lancet 360: $942-944$

Beral V, Million Women Study Collaborators (2003) Breast cancer and hormone-replacement therapy in the Million Women Study. Lancet 362: $419-427$

Bonithon-Kopp C, Benhamiche AM (1999) Are there several colorectal cancers? Epidemiological data. Eur J Cancer Prev 8(Suppl 1): S3-S12

Bossard N, Velten M, Remontet L, Belot A, Maarouf N, Bouvier AM, Guizard AV, Tretarre B, Launoy G, Colonna M, Danzon A, Molinie F, Troussard X, Bourdon-Raverdy N, Carli PM, Jaffre A, Bessaguet C, Sauleau E, Schvartz C, Arveux P, Maynadie M, Grosclaude P, Estève J, Faivre J (2007) Survival of cancer patients in France: The populationbased study from the Association of the French Cancer Registries study'. Eur J Cancer 43: $149-160$

Brenner H, Gefeller O, Greenland S (1993) Risk and rate advancement periods as measures of exposure impact on the occurrence of chronic diseases. Epidemiology 4: 229-236

Day N (1987) Cumulative rate and cumulative risk. In: Cancer Incidence in Five Continents Muir C, Waterhouse J, Mack T, Powell J, Whelan S, (eds) Vol V. IARC Scientific Publication No. 88, chapter 10 Lyon: International Agency for Research on Cancer

Faber A, Bouvy ML, Loskamp L, van de Berg PB, Egberts TC, de Jong-van den Berg LT (2005) Dramatic change in prescribing of hormone replacement therapy in The Netherlands after publication of the Million Women Study: a follow-up study. Br J Clin Pharmacol 60: 641-647

Fernandez E, Bosetti C, La Vecchia C, Levi F, Fioretti F, Negri E (2001) Sex differences in colorectal cancer mortality in Europe, 1955-1996. Eur J Cancer Prev 10: 299-300

Hersh AL, Stefanick ML, Stafford RS (2004) National use of postmenopausal hormone therapy: annual trends and response to recent evidence. JAMA 291: $47-53$

Johns LE, Houlston RS (2001) A systematic review and meta-analysis of familial colorectal cancer risk. Am J Gastroenterol 96: 2992-3003

Ko CW, Sonnenberg A (2005) Comparing risks and benefits of colorectal cancer screening in elderly patients. Gastroenterology 129: $1163-1170$

Lieberman D (2005) Race, gender, and colorectal cancer screening. Am J Gastroenterol 100: 2756-2758

Lieberman DA, Holub J, Eisen G, Kraemer D, Morris CD (2005) Utilization of colonoscopy in the United States: results from a national consortium. Gastrointest Endosc 62: 875-883

Lin OS, Kozarek RA, Schembre DW, Ayub K, Gluck M, Drennan F, Soon MS, Rabeneck L (2006) Screening colonoscopy in very elderly patients. JAMA 295: 2357-2365

Malila N, Anttila A, Hakama M (2005) Colorectal cancer screening in Finland: details of the national screening programme implemented in autumn 2004. J Med Screen 12: 28-32
McCashland TM, Brand R, Lyden E, de Garmo P, CORI research Project (2001) Gender differences in colorectal polyps and tumors. Am J Gastroenterol 96: $882-886$

Meissner HI, Breen N, Klabunde CN, Vernon SW (2006) Patterns of colorectal cancer screening uptake among men and women in the United States. Cancer Epidemiol Biomarkers Prev 15: 389-394

Parkin DM, Bray F, Ferlay J, Pisani P (2005) Global cancer statistics, 2002. CA Cancer J Clin 55: 74-108

Regula J, Rupinski M, Kraszewska E, Polkowski M, Pachlewski J, Orlowska J, Nowacki MP, Butruk E (2006) Colonoscopy in colorectal-cancer screening for detection of advanced neoplasia. N Engl J Med 355: 1863 1872

Ries LAG, Harkins D, Krapcho M, Mariotto A, Miller BA, Feuer EJ, Clegg L, Eisner MP, Horner MJ, Howlader N, Hayat M, Hankey BF, Edwards BK (eds) (2006) SEER Cancer Statistics Review, 1975-2003. Bethesda, MD: National Cancer Institute. http://seer.cancer.gov/csr/ 1975_2003/ based on November 2005 SEER data submission, posted to the SEER web site

Rossouw JE, Anderson GL, Prentice RL, Lacroix AZ, Kooperberg C, Stefanick ML, Jackson RD, Beresford SA, Howard BV, Johnson KC, Kotchen JM, Ockene J, Writing Group for the Women's Health Initiative Investigators (2002) Risks and benefits of estrogen plus progestin in healthy postmenopausal women. JAMA 288: $321-333$

Schmiegel W, Pox C, Adler G, Fleig W, Fölsch UR, Frühmorgen P, Graeven U, Hohenberger W, Holstege A, Junginger T, Kühlbacher T, Porschen R, Propping P, Riemann JF, Sauer R, Sauerbruch T, Schmoll H-J, Zeitz M, Selbmann H-K (2004) S3 Guidelines Colorectal Cancer 2004 [in German]. $Z$ Gastroenterol 42: 1129-1177

Seeff LC, Nadel MR, Klabunde CN, Thompson T, Shapiro JA, Vernon SW, Coates RJ (2004) Patterns and predictors of colorectal cancer test use in the adult US population. Cancer 100: 2093-2103

Smith RA, Cokkinides V, Eyre HJ (2006) American Cancer Society guidelines for the early detection of cancer, 2006. CA Cancer J Clin 56: $11-25$

Stewart RJ, Stewart AW, Turnbull PR, Isbister WH (1983) Sex differences in subsite incidence of large-bowel cancer. Dis Colon Rectum 26: 658-660

Vijan S, Hwang EW, Hofer TP, Hayward RA (2001) Which colon cancer screening test? A comparison of costs, effectiveness and compliance. Am J Med 111: $593-601$

WHO mortality data base (2006) Available from http://www-dep.iarc.fr/ [accessed October 15, 2006].

Winawer SJ, Fletcher R, Rex D, Bond J, Burt R, Ferrucci J, Ganiats T, Levin T, Woolf S, Johnson D, Kirk L, Litin S, Simmang C (2003) Colorectal cancer screening and surveillance: clinical guidelines and rationale - update based on new evidence. Gastroenterology 124: $544-560$ 